\title{
Leituras brasileiras para \\ crianças e jovens: entre o leitor, \\ a escola e o mercado
}

Regina Zilberman ${ }^{a}$

\begin{abstract}
Resumo
Os primeiros livros brasileiros dirigidos ao público infantojuvenil foram publicados no começo do século XIX, com intuito didático. A autonomia dessa produção materializa-se com Monteiro Lobato, a partir de 1920, época também de crescimento econômico e social. Desde então, expande-se a literatura infantil brasileira, em decorrência do aumento do mercado consumidor, adoção de políticas de estímulo à leitura, aquisição e distribuição de livros pelo governo, planos curriculares centralizados em temas transversais de interesse coletivo. O consumo de obras literárias é, pois, induzido pelos mecanismos do Estado e da escola. Não significa que estejam ausentes a produção espontânea, escolhida diretamente pelo público leitor, ou a criatividade. A literatura brasileira infantojuvenil, ao longo de sua história, exemplifica características do gênero em que se inscreve, como a relação entre as preferências do público leitor e as direções do mercado escolar, as possibilidades de criar para além do suporte impresso, a interação com outros meios de comunicação.
\end{abstract}

Palavras-chave: Literatura infantil; leitura; mercado do livro

Recebido em 23/10/2014 Aprovado em 02/11/2014

a Professora adjunta da Universidade Federal do Rio Grande do Sul. Email: reginaz@portoweb.com.br. 


\section{A escola e a literatura infantil e juvenil}

A literatura marca sua presença em sala de aula desde a educação infantil, antecipando o processo de letramento que ela poderá ou não vir a estimular, mas que transcorrerá posteriormente, nas primeiras séries no ensino fundamental. Os livros oferecidos a crianças ainda não alfabetizadas nem sempre tomam o formato usual, podendo ser impressos em pano ou em plástico, com a ilustração predominando sobre o texto, e seguidamente assumindo a expressão digital. Porém, porque lidam com ficção e apelam à fantasia de seu destinatário, pertencem ao campo literário, em especial ao campo da literatura para crianças e jovens.

É sob esse aspecto que a literatura se introduz na escola, mesmo quando se dirige a uma audiência ainda não leitora de matéria registrada pela escrita.

\section{A literatura para crianças e jovens e o mercado editorial}

Alguns números, sintetizados no quadro a seguir, representam bem a situação da literatura para crianças e jovens no Brasil da segunda década do terceiro milênio:

Quadro 1 - Literatura infantil e juvenil brasileira

\begin{tabular}{|c|c|c|c|}
\hline & $\mathbf{2 0 1 0}$ & $\mathbf{2 0 1 1}$ & $\mathbf{2 0 1 2}$ \\
\hline $\begin{array}{c}\text { Número de } \\
\text { exemplares }\end{array}$ & 70.291 .036 & 30.911 .591 & 47.413 .402 \\
\hline $\begin{array}{c}\text { Títulos } \\
\text { impressos }\end{array}$ & [não informado] & [não informado] & 11.011 \\
\hline $\begin{array}{c}\text { Participação no } \\
\text { mercado }\end{array}$ & $14,27 \%$ & $6,19 \%$ & $9,74 \%$ \\
\hline
\end{tabular}

Fonte: Produção e Vendas do Setor Editorial Brasileiro - Base 2012

(Câmara Brasileira do Livro, 2012)

A participação dos livros destinados a crianças e jovens no Brasil só é menor que a dos livros didático, que aparecem nas quantidades reproduzidas a seguir: 
Quadro 2 - Produção de livros didáticos

\begin{tabular}{|c|c|c|}
\hline & $\mathbf{2 0 1 1}$ & $\mathbf{2 0 1 2}$ \\
\hline Número de exemplares & 282.827 .709 & 214.250 .244 \\
\hline Títulos impressos & [não informado] & 10.276 \\
\hline Participação no mercado & $56,59 \%$ & $44,04 \%$ \\
\hline
\end{tabular}

Fonte: Produção e Vendas do Setor Editorial Brasileiro - Base 2012

(Câmara Brasileira do Livro, 2012)

O Censo Escolar da Educação Básica, divulgado em 2012 pelo Instituto Nacional de Estudos e Pesquisas Educacionais (INEP), apontou que a população de estudantes no Brasil é composta por aproximadamente cinquenta milhões de pessoas, estendendo-se da educação infantil ao ensino médio e incluindo os segmentos dedicados à Educação Especial e à Educação de Jovens e Adultos. (INEP, 2013) Considerando a quantidade de volumes destinados a crianças e jovens, impressos naquele ano, poder-se-ia supor que a cada um dos alunos matriculados foi previsto o consumo de, ao menos, um exemplar. A média fica mais alta, quando aproximada ao número de livros escolares produzidos.

Por mais de um ângulo, a produção impressa consagrada ao público estudantil lida com cifras dignas de destaque: a participação dos livros classificados como literatura infantil e juvenil alcança, e às vezes supera, os $10 \%$ dos consumidores; esse percentual é ultrapassado unicamente pela produção de livros didáticos, que orbitam em torno a $50 \%$ do mercado.

O próximo quadro resume o faturamento anual global da produção de livros no Brasil, discriminando a quantidade de exemplares impressos:

Quadro 3 - Faturamento global e exemplares comercializados

\begin{tabular}{|c|c|c|}
\hline Ano & Faturamento em R\$ & Exemplares \\
\hline 2010 & $4.505 .918 .296,76$ & 437.945 .286 \\
\hline 2011 & $4.837 .439 .173,31$ & $469.468,840$ \\
\hline 2012 & $4.984 .612 .881,04$ & 434.920 .064 \\
\hline
\end{tabular}

Fonte: Produção e Vendas do Setor Editorial Brasileiro - Base 2012

(Câmara Brasileira do Livro, 2012) 
Esse mercado, porém, não depende apenas da aquisição de livros de modo espontâneo ou motivado pela escola. $\mathrm{O}$ grande cliente é o Estado brasileiro, nas instâncias federal, estadual e municipal. O governo federal é o principal comprador, por meio de ações promovidas sobretudo pelo Ministério de Educação, como o Programa Nacional da Biblioteca na Escola (PNBE) e o Programa Nacional do Livro Didático (PNLD).

$\mathrm{O} P N B E$ destina-se à compra de livros voltados a crianças e jovens, ainda que as aquisições anuais nem sempre elejam apenas títulos dirigidos àquele público, sendo facultada também a inclusão que obras que colaboram com a ação do professor em sala de aula. O quadro 4 dá conta das negociações do PNBE junto às editoras brasileiras:

Quadro 4 - PNBE: Faturamento e exemplares comercializados

\begin{tabular}{|c|c|c|}
\hline Ano & Faturamento em $\mathbf{R} \$$ & Exemplares adquiridos \\
\hline 2010 & $70.901 .085,82$ & 13.376 .477 \\
\hline 2011 & $78.362 .657,49$ & 10.086 .824 \\
\hline 2012 & $70.992 .727,70$ & 11.353 .211 \\
\hline
\end{tabular}

Fonte: Produção e Vendas do Setor Editorial Brasileiro - Base 2012 (Câmara Brasileira do Livro, 2012)

As listas anuais de obras adquiridas com os recursos financeiros do Ministério da Educação incluem narrativas, poesia, dramaturgia, adaptações, novelas gráficas, etc. Os livros provêm, na maioria, de autores nacionais, congregando tanto nomes canônicos, quanto escritores e ilustradores que iniciaram suas carreiras na última década. Essa decisão fomenta, assim, não apenas a impressão de livros em grande quantidade, mas também estimula a dedicação à criação literária, prestigiando a literatura infantil e juvenil.

De uma parte, a interferência governamental tem um efeito perverso porque induz à produção de obras conforme temas e faixas etárias privilegiados por editais públicos. De outra, tais ações colaboram para o fortalecimento da industrial editorial e, sobretudo, para a profissionalização de escritores e ilustradores, conferindo à literatura infantil e juvenil do país invejável posição, se comparada a suas congêneres no plano da ficção e da poesia. 
Cabe rever a trajetória dessa literatura para verificar o que determinou o crescimento da confiança no gênero voltado a crianças e jovens, o qual nem sempre experimentou situação tão propícia.

\section{O primeiro século dos livros para crianças e jovens no Brasil}

Um dos primeiros livros destinados às crianças a circular no Brasil deve ter sido o Tesouro dos meninos, traduzido do francês por Mateus José da Rocha. A julgar pela observação de John Luccock, comerciante inglês que residiu na então colônia portuguesa entre 1808 e 1818, o livro tratava de "moral, virtude e boas maneiras" (LUCCOCK, 1975, p. 379). De 1818 é Leitura para meninos, que conteria "uma coleção de histórias morais relativas aos defeitos ordinários às idades tenras e um diálogo sobre a geografia, cronologia, história de Portugal e história natural". (CABRAL, 1881)

Leitura para meninos, provavelmente de José Saturnino da Costa Pereira, devia partilhar com Tesouro dos meninos a finalidade educativa, sobretudo moralizante, e a apresentação de histórias fictícias a serem contadas às crianças. Foi várias vezes reimpresso e não muito tempo depois do aparecimento da primeira edição: Alfredo do Vale Cabral registra as reedições de 1821, 1822 e 1824, sugerindo que o livro encontrou seu público, talvez entre os adultos que procuravam material, em uma obra provavelmente adequada à faixa etária dos consumidores, para ensinar as crianças a ler e adquirir padrões morais. Rubens Borba de Morais considera-a fundadora da literatura infantil brasileira: "A literatura infantil surge, em 1818, com uma obra que fez sucesso, pois foi reimpressa em 1821, 1822 e 1824. É um "livro de leitura", como se dizia antigamente: Leitura para os meninos..." (MORAES, 1993, V.1, p. XXIX) Que o público infantil começava a tomar forma nesse início do século XIX indica-o a tradução, em 1814, de Aventuras pasmosas do célebre Barão de Munkausen. Em 1847, o livro consta do catálogo da editora Laemmert, sinalizando a permanência do interesse que suscitava.

Apesar do começo auspicioso, são frequentes as denúncias de que faltava variedade aos livros indicados às crianças, especialmente na escola. Em 1850, o Tesouro dos meninos ainda circulava, ao lado do Simão de Nântua, provavelmente o livro 
mais difundido entre a infância brasileira do oitocentos. A circunstância de haver poucas obras adequadas à infância não significa que o mercado carecesse de potência. As escolas requeriam material impresso, e o governo ajudava a supri-las. Primitivo Moacyr relaciona os livros distribuídos em 1866 entre as escolas primárias do Rio de Janeiro, constando entre eles 652 volumes dos Contos de Schmid, ao lado de gramáticas, catecismos e tabuadas. Também reproduz os valores com que contava o governo para aquisição de livros: "2:000\$000 de réis consignados na lei do orçamento", estando disponíveis, para o ano seguinte, "4:000\$000", a serem gastos com a compra de "exemplares de história do Brasil, de que há falta, e bem assim de sistema métrico e ainda a aritmética de Coruja". (MOACYR, 1939, V. 2, p. 240)

O cônego Christoph von Schmid ocupa a posição best seller na segunda metade do século XIX. Elomar Tambara constata que, em 1881, 2775 volumes de seus contos são negociados para distribuição em escolas, ao lado dos livros de Abílio César Borges e de obras de conteúdo catequético. (TAMBARA). Essas compras concentram-se na província do Rio de Janeiro, alcançando, entre 1871 e 1884, 9040 volumes (incluídos os 2775 exemplares de 1881). Ao lado da popularidade impulsionada pelas compras governamentais das narrativas de Schmid, estão as fábulas, adaptadas para a língua portuguesa e para o leitor brasileiro por autores nascidos no país. Justiniano José da Rocha, em 1852, lançou a Coleção de fábulas imitadas de Esopo e de La Fontaine (...) oferecida à mocidade das escolas, livro que deve ter sido bem sucedido, pois foi reeditado em 1863 e 1873. Seguidor de La Fontaine foi seu tradutor, o Barão de Paranapiacaba, que, em 1883, publicou O primeiro livro das fábulas (...) para uso das escolas de instrução primária, reeditado em 1886.

Junto com os livros que destacam, no título, terem como alvo a escola, aparecem os que valorizam o destinatário. Contos infantis, de Adelina Lopes Vieira e Júlia Lopes de Almeida, é lançado em 1886 e adotado para uso das escolas primárias, conforme determinação da Instrução Pública Primária e Secundária do governo federal.

O marco editorial, porém, é o lançamento da Biblioteca Infantil, patrocinada pela Livraria Quaresma, cujo proprietário encomendou ao jornalista Figueiredo Pimentel, em 1894, a produção de uma coletânea de histórias de fadas, intitulada 
Contos da Carochinha. Mais uma vez o mercado consumidor mostrou-se apetente: no prefácio à $24^{\mathrm{a}}$ edição dos Contos $d a$ Carochinha, de 1958, rememora-se o sucesso alcançado desde o começo: a primeira edição "esgotou-se totalmente, em menos de um mês". Ao final da década de 1950, "perto de cem mil volumes corr[ia]m de mão em mão, em todos os Estados, em todas as cidades e vilas do Brasil" (EDITOR, 1958, p. 8-9) A introdução às Histórias do arco da velha, pertencente também ao catálogo da Biblioteca Infantil, informa que nenhum dos títulos da coleção teve "edição menor de dez mil exemplares". (LIVRARIA QUARESMA, 1959, p. 5)

O negócio dos livros para crianças, incipiente à época do Tesouro dos meninos e do Livro de Leitura, prospera, ao final do oitocentos. Contudo, faltavam autores e temas brasileiros, e esses começam a se manifestar no começo do século seguinte, quando se publicam, em 1901, Porque me ufano de meu país, de Afonso Celso, em 1904, Contos pátrios, de Olavo Bilac e Coelho Neto, em 1907, Histórias da nossa terra, de Júlia Lopes de Almeida, e em 1910, Através do Brasil, de Olavo Bilac e Manuel Bonfim. Os títulos bastam para indicar a opção pelo nacionalismo, como se a literatura infantil só tivesse condições de se afirmar no país se, ao mesmo tempo, afirmasse o próprio país.

Os livros de poesia reiteraram o paradigma, ainda que seus títulos - Poesias infantis (1904), de Olavo Bilac, ou Alma infantil (1912), de Francisca Júlia e Júlio César da Silva - não expusessem o propósito nativista, exibido nos versos daqueles autores. Graças a essa escolha, a literatura infantil brasileira manteve seus vínculos com a escola, garantindo o resultado agora quase centenário: um público cativo, um mercado consumidor assegurado.

\section{A modernização do livro e a modernidade da literatura para crianças}

Em 1919, Thales de Andrade publica Saudade. Destinado ao público infanto-juvenil, o livro traz marcas que o distinguem do até então produzido: o relato, em primeira pessoa, é memorialista, recuperando os acontecimentos relativos à vida do protagonista no campo, depois na cidade e, por fim, outra vez no meio rural. Identifica-se uma visão nostálgica em relação ao universo agrícola em que se deu a formação da 
personagem, sentimento decorrente talvez da consciência de que aquela experiência, apesar de suas qualidades positivas, era irrecuperável.

A obra foi muito bem sucedida no mercado, e pelo menos até 2002 continuava figurando no catálogo de uma editora brasileira. Cabe frisar que o início bastante auspicioso de sua carreira deveu-se a ação do governo do Estado de São Paulo, que patrocinou a tiragem inicial de quinze mil exemplares. Outros vinte mil volumes foram impressos pelo Jornal de Piracicaba, da cidade natal do escritor.

Essa circunstância não torna o livro de Thales de Andrade menos importante, até porque a dependência do Estado remontava ao tempo do imperador e prolongar-se-ia até a atualidade. $\mathrm{O}$ que confere a Saudade a condição de marco inaugural é o fato de a narrativa ser produto da imaginação do escritor, rompendo o ciclo das adaptações que, desde as Aventuras pasmosas do célebre Barão de Munkausen, passaram depois pelas mãos de Figueiredo Pimentel, além de terem sido praticadas, antes, por Carlos Jansen, e, na sequência, por Arnaldo de Oliveira Barreto.

Andrade, como Jansen, atuava no magistério; como Barreto, formara-se na Escola Normal e colaborava com a redação de livros destinados ao ensino. Seus vínculos com a escola amarravam-no por demais ao sistema até então implementado, segundo o qual um texto era escrito e editado para ser lido por estudantes, mesmo quando essa ação ocorresse fora da sala de aula.

É por romper esse círculo vicioso, introduzindo a visão empresarial, que Monteiro Lobato supera o papel pioneiro desempenhado por Thales de Andrade. A menina do narizinho arrebitado, com que, em 1920, Lobato estreia como autor voltado às crianças leitoras, inicia sua trajetória repetindo os passos de Saudade; mas, logo a seguir, ultrapassa os limites então estabelecidos, abrindo novos horizontes para o gênero em que se inscrevia.

A menina do narizinho arrebitado apareceu pela primeira vez no formato de $29 \times 22 \mathrm{~cm}$, com capa ilustrada e cartonada. Os desenhos, devidos a Voltolino, eram coloridos, e o volume, com 43 páginas, procurava assemelhar-se aos livros oferecidos nas proximidades do Natal, para presentear as crianças. Em 1921, Monteiro Lobato reeditou a história, acrescentada de 
episódios novos; simplificou o nome para Narizinho arrebitado e estendeu o livro para 181 páginas. O formato também foi alterado, aproximando-se ao dos livros didáticos da época, em $18,5 \times 13,5 \mathrm{~cm}$. As ilustrações ainda provinham de Voltolino, mas, nesta versão, eram impressas em preto sobre o branco. Mais importante que essas modificações foi o aumento da tiragem, que passou para 50.500 exemplares. Esse número extraordinário, mesmo em nossos dias, deveu-se à compra do livro pelo governo de São Paulo, que o destinou a rede escolar.

Em sua estreia, Lobato repete as duas estratégias em voga em seu tempo: a publicação de histórias dirigidas a crianças em álbuns de Natal, como, a seu tempo, fizera Hans Christian Andersen, por exemplo; e a parceria com o Estado, cliente com o qual se podia contar. Por essa razão, não surpreende que, um ano depois, Lobato publique Fábulas, livro aprovado pela Diretoria de Instrução Pública de São Paulo para uso didático, agindo, como fizeram à época da monarquia, Justiniano José da Rocha e o Marquês de Paranapiacaba. Fábulas eram leitura considerada apropriada às crianças desde a transformação das narrativas de La Fontaine em literatura infantil, de modo que elas fomentarão por muito tempo a indústria nacional do livro.

Monteiro Lobato, porém, não era professor, não atuava junto a instituições de ensino, não escrevia livros escolares, nem dirigia coleções voltadas ao público estudantil, como fazia seu conterrâneo Thales de Andrade, responsável pela série Encanto e Verdade, da editora Melhoramentos. Ele já tinha sido promotor público em Areias, cidade do interior de São Paulo, proprietário de uma fazenda e escritor de libelos como "A velha praga" e de obras ficcionais, como os contos de Urupês, lançado em 1918. Nenhuma dessas profissões e tarefas levara-o para o campo da educação; pelo contrário, ele preferira investir os recursos alcançados com a venda de suas terras na impressão de livros, primeiramente por meio da Revista do Brasil, depois por meio da fundação da editora a que dera seu nome: Monteiro Lobato \& Cia., em 1920.

Era, pois, um empresário, e essa mudança de posição determina transformações em sua concepção sobre a produção e a circulação de livros. Na perspectiva da produção, levará em conta não apenas a invenção de uma narrativa e de personagens que a vivenciam, mas também a apresentação material do suporte da escrita; na perspectiva da circulação, a consciência 
de que cabe convencer um público anônimo, aleatório e distante a comprar o objeto que ele oferece, e não outro, determina a adoção de estratégias específicas de vendas, para além da dependência ao governo e aos propósitos da educação.

As táticas que empregou mostraram-se eficientes, ainda que tivessem passado por reiterados ups and downs, ao longo dos 25 anos dedicados a escrever para crianças, colaborando para o avanço do gênero literário que escolheu, não apenas por criar um universo literário de grande impacto na cultura brasileira, mas também porque evidenciou o ângulo mercantil de todo produto destinado ao consumo, seja ele de natureza estética ou meramente pragmática.

A trajetória de Monteiro Lobato parece fazer dele um homem-orquestra. Contudo, ele não estava só, embora pudesse sintetizar o que ocorria no período.

Desde o final do século XIX, São Paulo liderava o desenvolvimento econômico do país. Por efeito do enriquecimento decorrente da produção e exportação do café, dera-se a expansão industrial, que favorecia o crescimento urbano. Fortalecia-se uma classe média que congregava profissionais liberais, servidores públicos e comerciantes, ao lado do operariado, que encontrava emprego nas fábricas situadas na periferia das cidades. O quadro econômico e social repetia-se, em menor escala, em outros centros urbanos, incluindo a Capital Federal. No Rio de Janeiro, trabalhadores, funcionários públicos, profissionais portadores de títulos universitários engrossavam a população consumidora de bens industrializados, entre os quais o livro. A indústria editorial ultrapassa as fronteiras que a limitavam ao mercado escolar, estimulando a publicação não apenas de traduções de ficcionistas estrangeiros, mas também a difusão do escritor nacional, especialmente os da geração comprometida com os movimentos modernistas.

Monteiro Lobato, nos anos 1920, integra um contexto que faculta a ele agir não apenas como criador e artista, mas também como industrial. Ao longo da década, abandona essa função, mas deixa um legado herdado pelas editoras que fundou, como a Nacional, em 1925, e pelas que acompanharam seus passos, como a José Olympio, no Rio de Janeiro, ou a Globo, em Porto Alegre, que se consolidaram a partir dos anos $1930 \mathrm{e}$ cujas atividades estenderam-se até os anos 1970. 
O escritor, portanto, indicou os caminhos para a produção de livros brasileiros, e no interior desse processo colocou a literatura para crianças e jovens. E, se era novo o processo de produção, seu resultado - a literatura - também deveria ser original. Por isso, pode ter buscado reproduzir, com os primeiros livros, o que se fazia nas décadas iniciais do século XX. Mas já no livro com que inaugura a carreira de autor para a infância e juventude introduz novidades, fomentadas ao longo de sua trajetória criativa.

A menina do narizinho arrebitado e sua sucessora, Narizinho arrebitado, sintetizam, pois, os dois tempos - o do passado e o do futuro. Do passado, incorpora o sistema de produção: um álbum natalino, depois, um livro escolar. Importa também o cenário da ação - o sítio de Dona Benta, espaço rural idílico, resíduo talvez da infância do autor, educado na fazenda do avô, mas também paisagem do já então popular Saudade, de Thales de Andrade. Porém, o autor não se satisfaz com isso, e projeta para o futuro um conjunto de possibilidades que consagrará suas obras literárias.

Primeiramente, desdenha o saudosismo de que o livro de Andrade está impregnado. Ainda que o sítio do Picapau Amarelo não se apresente como a unidade produtiva em que se converte a partir de O poço do Visconde, de 1937, as personagens que habitam o lugar mostram-se plenas de iniciativas e ideias novas. Além disso, estão afinadas com a modernidade dos anos 1920, representada pelo cinema e traduzida, no livro, pela presença de Tom Mix em meio às aventuras de Narizinho. Mais adiante, em O gato Félix, de 1928, é o herói de popular história em quadrinhos que interage com os moradores do sítio.

Admirador das manifestações da cultura de massa e consciente de que seria infrutífero confrontá-las, Lobato prefere combater as figuras tradicionais dos contos de fadas. Em Cara de coruja, de 1928, o narrador relata o acolhimento, por Dona Benta, das princesas dos contos europeus, que desejam escapar à servidão imposta por Dona Carochinha. Em outros episódios, personagens da renovada literatura infantil europeia, como Pinóquio e Peter Pan, comparecem indiretamente no universo fíctício de Lobato, ao protagonizarem respectivamente $O$ irmão de Pinóquio, de 1929, e Pena de papagaio, de 1930. 
As estratégias literárias adotadas são, por definição, renovadoras: o escritor carnavaliza a tradição, ao mesmo tempo em que integra, por meio da intertextualidade, procedimentos artísticos com os quais concorda e aos quais deseja equiparar sua obra. Ao mesmo tempo, vale-se da metalinguagem para discutir o processo criativo utilizado, sem que caia nos pecados do didatismo e da doutrinação. Pelo contrário, se há algo que Lobato preza é a independência - atitude que associa à inteligência, e de que a boneca Emília, a figura que corporifica sua visão do mundo, expressa desde o começo de sua existência fictícia.

Os livros são, pois, em princípio transgressivos, já que contradizem a tendência a reforçar comportamentos socialmente aceitáveis, o que agradava pais e professores, garantindo o acolhimento pela escola, por consequência, a venda para o governo. Lobato, ao inverter o modelo, propunha a rebeldia, $\mathrm{o}$ questionamento das ideias prontas, o compromisso com o progresso social e econômico. Preferia tomar partido de crianças e jovens, em vez de afagar os adultos, e não poucas vezes, em suas narrativas, as personagens que corporificam a mocidade desautorizam os mais velhos, representados inicialmente por Dona Benta e Tia Nastácia, depois por instituições como o Estado e o poder.

Escolher a ótica de seus jovens leitores, e mesmo assim não falar em nome deles, custou caro para Lobato. Enquanto ele viveu, seus livros (exceto o primeiro) não foram adquiridos por órgãos públicos; a História do mundo para crianças, de 1933, foi censurada no Brasil e proibida no Portugal salazarista. Nos anos 1950, o escritor, já falecido, foi acusado de fomentar o comunismo, e os livros foram proscritos de muitas escolas católicas. Não significa, porém, que não tenham vendido bastante: prestação de contas, datada de 1941 e enviada ao escritor por Octales Marcondes Ferreira, proprietário da Companhia Editora Nacional, indica que até aquela data tinham sido comercializados 1.029.500 exemplares de seus livros (infantis, adultos, adaptações e traduções), rendendo-lhe 5.785:000 000 réis, na moeda da época. (Cedae MLb 3.2.00407cx8)

Ao lado de Lobato, outros escritores impulsionaram a literatura dirigida a crianças e jovens. Viriato Correia, Erico Verissimo, Thales de Andrade, Ofélia e Narbal Fontes, Malba Tahan, Orígenes Lessa, mais adiante Maria José Dupré, Lúcia Machado de Almeida, Jerônimo Monteiro, Francisco Marins 
foram contemporâneos e sucessores do criador do sítio do Picapau Amarelo, compartilhando seus achados literários e o público que ele seduziu. Mas não propuseram novas formas de lidar com o mercado consumidor, que continuava a crescer e que, na falta de novidades, orientava-se para a cultura de massa, representada sobretudo pelas histórias em quadrinho. Ignorando a solução de Monteiro Lobato, que, ao invés de contrariar os meios de comunicação de massa, aliara-se a ele, acabaram por estabelecer uma rivalidade, posição incorporada pelo sistema educacional. Produção e público caminhavam sobre trilhas distintas e, às vezes, opostas. Advém daí o retrocesso da literatura infantil, bem como o anacronismo encontrável em boa parte da obra dos autores ativos sobretudo entre 1950 e 1970.

\section{Um novo início, um final pós-moderno}

O desenvolvimento industrial das primeiras décadas iniciais do século $X X$, conforme um ritmo que não esmorece nos anos 1950, determinou o deslocamento de contingentes de população do campo para a cidade, e do Nordeste para o Sul. A mudança da Capital Federal, do Rio de Janeiro para Brasília, também suscita a mobilização de pessoas, primeiramente dos trabalhadores envolvidos na construção da cidade, e após sua inauguração, em 1960, dos servidores públicos, profissionais liberais, políticos e membros do staff governamental.

As alterações econômicas e políticas explicam a nova composição da sociedade. Se, até o começo do século XX, a base econômica provinha do campo, agora é a produção fabril, voltada ao mercado interno, que movimenta o mundo financeiro. Por outro lado, o país não se liberta dos laços de dependência, não mais à metrópole colonial ou ao imperialismo britânico, como ocorrera, respectivamente, até a independência, em 1822, e na sequência, durante ao século XIX, mas ao capitalismo norte-americano, proprietário dos meios de produção industrial instalados no Brasil, especialmente depois do final da segunda guerra.

No começo da segunda metade do século XX, o Brasil passa por conflitos que colocam frente à frente as tendências de esquerda, de pendor nacionalista, e de direita, de orientação autoritária. Essa, em 1964, ocupou o Estado por efeito de golpe 
apoiado pelo Exército; em 1985, retorna o poder civil, regularizando aos poucos o sistema democrático e acomodando os interesses dos distintos setores da economia e da sociedade.

A cultura, em especial a literatura, incluída aquela voltada a crianças e jovens, acompanha a passagem da democracia à ditadura, e o retorno àquela. Não cessa de manifestar suas aspirações à liberdade de expressão, mesmo em momentos críticos de repressão e censura. E beneficia-se de dois fatores que caracterizam o Brasil contemporâneo: o crescimento da população urbana, acompanhado do aumento do número de pessoas alfabetizadas.

A política desenvolvimentista vigente desde os anos 1950, e intensificada pelo governo militar, apoiava-se, de uma parte, na edificação de obras públicas de grande porte (rodovias, hidroelétricas, habitação popular), de outra, no acolhimento do capital internacional, representado por indústrias e bancos multinacionais. O país modernizava sua infraestrutura, ao mesmo tempo em que mantinha a dependência ao poder econômico estrangeiro. Esse, por sua vez, requeria operários capacitados e clientela preparada, possível desde que escolarizado.

A década de 1970 testemunhou uma ampla reforma de ensino que tornou obrigatório o ensino fundamental, com a duração de oito anos. $\mathrm{O}$ analfabetismo, elevado ainda nessa época, comprometia o projeto modernizador do Estado, que, autoritário, pôde impô-lo em todas as regiões do país. A indústria do livro, também ela em processo crescente de desnacionalização, foi mobilizada a responder à nova demanda, o que favoreceu sobremodo o segmento do livro escolar.

A literatura infantil foi igualmente beneficiada, porque a nova legislação facultava o emprego de livros para criança em sala de aula. A necessidade de fornecer material literário aos estudantes levou, em um primeiro momento, à reciclagem de livros lançados nas décadas anteriores. Entre 1970 e 1980, reaparecem, com grande repercussão, livros de Maria José Dupré, Lúcia Machado de Almeida e Orígenes Lessa. Aos poucos, porém, introduz-se a nova geração: a de Ziraldo, nos anos 1960, a de Fernanda Lopes de Almeida, Lygia Bojunga, Ana Maria Machado, Ruth Rocha, Marina Colasanti, João Carlos Marinho, Bartolomeu Campos Queirós, Joel Rufino dos Santos, nos anos 1980, a de Pedro Bandeira, Ricardo Azevedo, Marcos Rey, na década seguinte. 
A participação do Estado no processo de expansão e diversificação da literatura para crianças e jovens não se limitou a essa intervenção à distância. As denúncias de que a escola não preenchia suas funções de modo satisfatório, aparentando ser incapaz de colaborar para a formação de leitores proficientes, e a reivindicação de que fosse democratizado o acesso ao livro obrigaram o governo a tomar iniciativas no sentido de sanar essas carências. Nos anos entre 1970 e 1990, as medidas adotadas voltaram-se principalmente à aquisição e à distribuição de livros didáticos. Porém, já em 1984, o programa Salas de Leitura buscava reorientar essa prática, valorizando a produção destinada ao público infanto-juvenil. Foi sucedido, em 1997, pelo Programa Nacional Biblioteca na Escola (PNBE), cujas consistência e continuidade são garantidas por Resolução emanada no Fundo Nacional de Desenvolvimento da Educação (FNDE).

É graças sobretudo à ação do PNBE que o setor editorial brasileiro voltado à literatura infanto-juvenil apresenta os números robustos reproduzidos nos quadros 1 a 4 . Pela mesma razão, aumentou significativamente nas últimas décadas a quantidade de editoras, marcas e selos dirigidos à produção cultural voltada a crianças, adolescentes e jovens adultos. Outro dos resultados é a transferência de editoras brasileiras a empresas estrangeiras, acompanhando o processo de agrupamento verificado no plano internacional.

O mercado brasileiro de livros para crianças não se movimenta, pois, de modo voluntarista, sendo muitas de suas ações induzidas pelo poder público. Essa indução evidencia-se também quando obras são levadas a se ajustar aos critérios das compras anuais comandadas pelo Ministério da Educação ou quando se favorecem temas valorizados na escola, na esteira das determinações pedagógicas, como os Parâmetros Curriculares Nacionais (PCNs), provenientes do sistema de ensino.

As criações literárias individuais, porém, não estão atreladas às demandas públicas do Estado. A liberdade de escrever e de manifestar ideias pessoais, de aderir a poéticas de vanguarda e de providenciar experiências artísticas é exercida por cada um dos autores que compõem o patrimônio atual da literatura infanto-juvenil brasileira. Além disso, os escritores parecem comprometidos com um ideal que remonta à prática literária de Monteiro Lobato - desejam interagir com os leitores e representar seus anseios e aspirações. 
Esse processo toma formas diversificadas e mostra-se permanentemente em mutação, afinando-se à poética pós-moderna, de que é testemunho legítimo. Uma de suas expressões é o experimentalismo metalinguístico, motivando o diálogo com o repertório de leituras e com o acervo cultural do leitor, a exemplo de Um homem no sótão, de Ricardo Azevedo, ou O fantástico mistério de Feiurinha, de Pedro Bandeira. Outros procedimentos são o recurso à hipertextualidade e o rompimento com as fronteiras materiais do suporte impresso, como fazem Sergio Capparelli, Angela Lago, Roger Mello, Luís Dill e Leo Cunha.

Os números reproduzidos nos quadros 1 a 4 sugerem que a literatura infanto-juvenil brasileira completa seu segundo centenário na condição de um sistema independente e sólido. Constitui um sistema porque dispõe de canais próprios de produção, distribuição e circulação, autores vocacionados para o gênero e linhas de criação variadas e singulares. Os livros são oferecidos ao mercado, repartidos em temas distintos, destinados a faixas etárias definidas e realizados segundo técnicas específicas, que se modificam em consonância com o público a que se destina.

Beneficiários são autores e leitores. Os primeiros, porque podem se profissionalizar, sem necessariamente ter de suplementar os rendimentos com atividades não literárias. Por isso, autores como Ziraldo, Pedro Bandeira e Ana Maria Machado há algum tempo ultrapassaram a marca do primeiro milhão de livros comercializados. Os segundos, porque dispõem de um catálogo rico em qualidade e diversidade, acolhendo tanto livros privilegiados em compras públicas, quando modalidades ainda não canônicas, como a fantasy fiction, bastante frequentada pelo público juvenil.

Em 1984, Pedro Bandeira publicou A droga da obediência (1984), novela reeditada, com ligeiras diferenças, em 2003, em que narra a inconformidade dos heróis, jovens estudantes de uma escola de elite, com o sistema impositivo adotado pela instituição em que estavam matriculados. Os rapazes e as moças que acionam o enredo acabam suplantando o diretor autoritário, que desejava submetê-los a uma droga química que provocaria sujeição e dependência. À obediência, eles propõem a rebeldia e a liberdade. 
Nada mais representativo da produção para crianças e jovens na atualidade. A "droga da obediência" não é consumida nem pela sociedade, nem pela literatura nacional, e o catálogo destinado à infância, adolescência e juventude é exemplo desse posicionamento insubmisso, em busca permanente por novos caminhos e veredas.

\section{REFERÊNCIAS}

CABRAL, Alfredo do Vale. Anais da Imprensa Nacional do Rio de Janeiro de 1808 a 1822. Rio de Janeiro: Tipografia Nacional, 1881. EDITOR. Prefácio. In: PIMENTEL, Alberto Figueiredo. Contos da Carochinha. 24. ed. Rio de Janeiro: Quaresma, 1958.

INEP. Censo da educação básica: 2012. Brasília: INEP, 2013.

LIVRARIA QUARESMA LTDA. Ao leitor. In: PADILHA, Viriato. Histórias do Arco da Velha. Rio de Janeiro: Quaresma, 1959.

LUCCOCK, John. Notas sobre o Rio de Janeiro e partes meridionais do Brasil. Belo Horizonte: Itatiaia; São Paulo: EDUSP, 1975

MOACYR, Primitivo. A instrução e as províncias. (Subsídios para a história da educação no Brasil). 1835-1889. São Paulo: Nacional, 1939. V. 2.

MORAES, Rubens Borba de. A Impressão Régia do Rio de Janeiro: origens e produção. In: CAMARGO, Ana Maria de Almeida; MORAES, Rubens Borba de. Bibliografia da Impressão Régia do Rio de Janeiro. São Paulo: EDUSP; Kosmos, 1993. V 1.

Produção e Vendas do Setor Editorial Brasileiro - Base 2012. Câmara Brasileira do Livro; Sindicato Nacional de Editores de Livro; Fundação Instituto de Pesquisas Econômicas. In: http:// www.snel.org.br/dados-do-setor/producao-e-vendas-do-setoreditorial-brasileiro. Acesso em 26 de maio de 2014.

TAMBARA, Elomar. Livros de leitura nas escolas de ensino primário no século XIX no Brasil. http://26reuniao.anped. org.br/trabalhos/elomarantoniotambara.rtf. Acesso em 21 de janeiro de 2009. 


\begin{abstract}
Brazilian readings for children and youth: between the reader, the school and the market

The first Brazilian books for the youth were published in the beginning of the nineteenth century, with didactic purposes. The autonomy of this literature materialized with Monteiro Lobato, in the twenties, also a time of economic and social growth. Since then, the Brazilian children's literature expands due to the increase of the consumer market, the embracing of policies to encourage reading, purchace and distribution of books by the government, curricula centered on crosscutting issues of collective interest. Consumption of literary works is therefore induced by State and school. That does not mean they are missing the spontaneous production, directly chosen by the readership, or creativity. Brazilian children's literature throughout its history illustrates characteristics of the genre in which it is included, as the relationship between the preferences of the readership and the directions of the school market, the possibilities of creating beyond the print support, the interaction with other media.
\end{abstract}

Keywords: Children literature; Reading; Book industry 